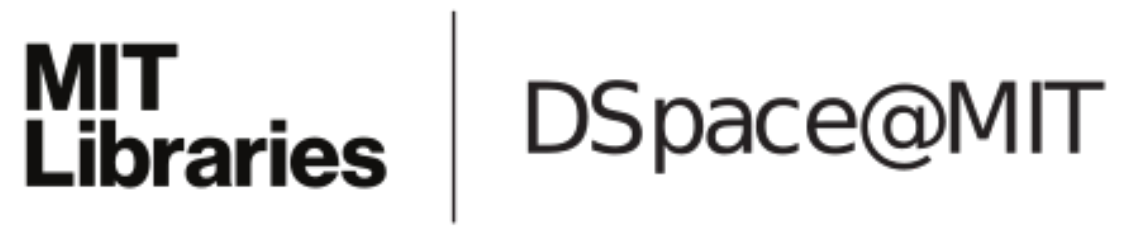

\author{
MIT Open Access Articles
}

\section{Dynamic mechanical properties of the tissue-engineered matrix associated with individual chondrocytes}

The MIT Faculty has made this article openly available. Please share how this access benefits you. Your story matters.

Citation: Lee, BoBae et al. “Dynamic mechanical properties of the tissue-engineered matrix associated with individual chondrocytes." Journal of Biomechanics 43 (2010): 469-476. Web. 26 Oct. 2011. (c) 2010 Elsevier Ltd.

As Published: http://dx.doi.org/10.1016/j.jbiomech.2009.09.053

Publisher: Elsevier Ltd.

Persistent URL: http://hdl.handle.net/1721.1/66592

Version: Author's final manuscript: final author's manuscript post peer review, without publisher's formatting or copy editing

Terms of use: Creative Commons Attribution-Noncommercial-Share Alike 3.0 


\title{
Dynamic mechanical properties of the tissue-engineered matrix associated with individual chondrocytes
}

\author{
BoBae Lee ${ }^{a}$, Lin Han ${ }^{a}$, Eliot H. Frank ${ }^{b}$, Susan Chubinskayac ${ }^{C}$, Christine Ortiz ${ }^{a}$, and Alan J. \\ Grodzinskyb,d,e,f, ${ }^{*}$ \\ aDepartment of Materials Science and Engineering, Massachusetts Institute of Technology, 77 \\ Massachusetts Avenue, Cambridge, MA 02139, USA \\ ${ }^{b}$ Center for Biomedical Engineering, Massachusetts Institute of Technology, 77 Massachusetts \\ Avenue, Cambridge, MA 02139, USA \\ 'Department of Biochemistry, Rush University Medical Center, Chicago, IL 60612, USA \\ dElectrical Engineering and Computer Science, Massachusetts Institute of Technology, 77 \\ Massachusetts Avenue, Cambridge, MA 02139, USA \\ eMechanical Engineering, Massachusetts Institute of Technology, 77 Massachusetts Avenue, \\ Cambridge, MA 02139, USA \\ fBiological Engineering, Massachusetts Institute of Technology, 77 Massachusetts Avenue, \\ Cambridge, MA 02139, USA
}

\section{Abstract}

The success of cell-based tissue engineering approaches in restoring biological function will be facilitated by a comprehensive fundamental knowledge base of the temporal evolution of the structure and properties of the newly synthesized matrix. Here, we quantify the dynamic oscillatory mechanical behavior of the engineered matrix associated with individual chondrocytes cultured in vitro for up to 28 days in alginate scaffolds. The magnitude of the complex modulus $\left(\left|\mathrm{E}^{*}\right|\right)$ and phase shift $(\delta)$ were measured in culture medium using Atomic Force Microscopy (AFM)-based nanoindentation in response to an imposed oscillatory deformation (amplitude $\sim 5 \mathrm{~nm}$ ) as a function of frequency $(f$ $=1-316 \mathrm{~Hz})$, probe tip geometry $(2.5 \mu \mathrm{mm}$ radius sphere and $50 \mathrm{~nm}$ radius square pyramid $)$, and in the absence and presence growth factors (GF, insulin growth factor-1, IGF-1, and osteogenic protein-1, OP-1). |E*| for all conditions increased nonlinearly with frequency dependence approximately $f^{1 / 2}$ and ranged between $\sim 1-25 \mathrm{kPa}$. This result, along with theoretical calculations of the characteristic poroelastic relaxation frequency, $f_{\mathrm{p}},(\sim 50-90 \mathrm{~Hz})$ suggested that this time-dependent behavior was governed primarily by fluid flow-dependent poroelasticity, rather than flowindependent viscoelastic processes associated with the solid matrix. $\left|\mathrm{E}^{*}(f)\right|$ increased, $\delta(f)$ decreased, and the hydraulic permeability, $\mathrm{k}$, decreased with time in culture and with growth factor treatment.

(c) 2009 Elsevier Ltd. All rights reserved.

*Corresponding Author: Alan J Grodzinsky 77 Massachusetts Avenue, NE47-377 Cambridge, MA 02139 Phone: (617) 253-4969 Fax: (617) 258-5239 alg@mit.edu.

Publisher's Disclaimer: This is a PDF file of an unedited manuscript that has been accepted for publication. As a service to our customers we are providing this early version of the manuscript. The manuscript will undergo copyediting, typesetting, and review of the resulting proof before it is published in its final citable form. Please note that during the production process errors may be discovered which could affect the content, and all legal disclaimers that apply to the journal pertain.

Conflict of Interest Statement

None 
This trend of a more elastic-like response was thought to be associated with increased macromolecular biosynthesis, density, and a more mature matrix structure/organization.

\section{Keywords}

Chondrocytes; AFM; Dynamic compression; Pericellular matrix; Growth factors; Nanomechanics; Tissue Engineering

\section{Introduction}

Cell-based tissue engineering holds great potential for therapies involving regeneration and/or replacement of damaged cartilage. Such approaches typically involve seeding cells (e.g., chondrocytes, stem cells) within macromolecular scaffolds or in scaffold-free environments and subjecting them to stimulatory biochemical and/or mechanical factors in vitro to promote synthesis and growth of neo-tissue for subsequent implantation in vivo. The ultimate goal and challenge is to produce a material with structural, biochemical and biomechanical properties similar enough to healthy cartilage so that upon maturation in vivo it can restore physiological function. To achieve this objective, it is important to understand the temporal evolution of the properties of the newly synthesized matrix. At early stages, matrix is formed around individual cells within the scaffold and these cell-matrix composites are often isolated from each other. As culture time increases, growth of neighboring cell-associated matrices leads to the formation of a more continuous neo-tissue which undergoes further evolution in structure and properties in vitro or in vivo. Throughout this process, the cell-associated matrix is important in facilitating cell signaling and mechanotransduction (Millward-Sadler 2000; Millward-Sadler 2004). Knowledge of the properties of the in vitro-generated matrix provides an assessment of the quality and ultimate success of a given tissue engineering approach and has great potential to be utilized for optimization.

Recently, we reported atomic force microscope (AFM)-based indentation of the newly synthesized cell-associated matrices of individual chondrocytes to quantify their quasistatic mechanical properties ( $\mathrm{Ng}$ 2007). This approach provides an advantage over macroscopic testing of the entire tissue-engineered construct, which is complicated by the response of the cells and scaffold, a significant effect at early times (Buschmann 1995). In addition, such local measurements enable the quantification of cell-to-cell heterogeneity and the tissue engineering process in general, while macroscopic experiments yield a homogenized response. For chondrocytes cultured in fetal bovine serum (FBS)-supplemented medium in alginate scaffolds, the stiffness of the newly-formed cell-associated matrix increased from $\sim 0.1 \mathrm{kPa}$ on day 7 to $0.17 \mathrm{kPa}$ by day 28 ( $\mathrm{Ng} 2007)$, a value much less than that of the pericellular matrix of mature intact cartilage chondrons ( $\sim 60 \mathrm{kPa}$ ) (Alexopoulos 2003), as well as cartilage extracellular matrix ( 1 MPa) (Kim 1995). The use of insulin-like growth factor-1 (IGF-1) and osteogenic protein-1 (OP-1) supplementation significantly increased matrix stiffness $\sim 25$-fold to $4.15 \mathrm{kPa}$ on day 28 compared to FBS culture on day 28 , consistent with observed increases in total GAG accumulation, and indicative of a more mature structure $(\mathrm{Ng} 2007)$.

Several previous studies have focused on measurement of the time-dependent mechanical behavior of chondrocytes having no PCM e.g., using transient nanomechanical testing via micropipette aspiration (Trickey 2004), AFM-based nanoindentation (Darling 2007), dynamic osmotic loading (Chao 2005), optical tweezers (Huang 2003), and creep cytoindentation (Shieh 2006). In contrast, the present study investigates the dynamic oscillatory mechanical behavior (Mahaffy 2000; Alcaraz 2003; Mahaffy 2004; Park 2005; Smith 2005) of the cell-associated matrices of individual chondrocytes cultured in alginate scaffolds up to 28 days. Such timedependent behaviors are important because tissue-engineered constructs implanted in vivo are 
expected to undergo cyclic and impact loading that includes frequency components as high as $1 \mathrm{kHz}$, just as native cartilage does (Shepherd 1997). Given the known hydrated and porous microstructure of the tissue-engineered cell-associated matrix (DiMicco 2007), rate-dependent poro-viscoelastic processes are expected (Kim 2008). The objectives of this study were (1) to establish the experimental and theoretical methodologies for quantifying the dynamic mechanical properties of newly developed tissue-engineered matrix associated with single cells, (2) to investigate the temporal evolution of these properties with increasing time in 3D alginate gel culture, and (3) to quantify the effect of specific growth factors (IGF-1 and OP-1) on the dynamic mechanical functionality of the newly developed matrix.

\section{Materials and Methods}

\section{Cell source and culture}

Chondrocytes were obtained from femoral condyles of 1-2 week old bovine calves and seeded into $2 \%$ alginate scaffolds, as described previously ( $\mathrm{Ng} 2007$ ). Cell-seeded alginate beads were maintained either in high-glucose Dulbecco's Modified Eagle Medium (DMEM) with 10\% FBS or in mini-ITS (29 $\mathrm{ng} / \mathrm{mL}$ insulin, $2 \mu \mathrm{g} / \mathrm{ml}$ transferrin, $2 \mathrm{ng} / \mathrm{ml}$ sodium selenite) with the combination of IGF-1 (100 ng/mL) and OP-1 (100 ng/mL) (growth factor (GF) culture) (Loeser 2003). On days $7,14,21$, and 28 , cells were released from beads and suspended with highglucose DMEM. Previous studies demonstrated that, under these same culture conditions, the cell-associated matrix was $\sim 3 \mu \mathrm{m}$ thick from day 7-28 ( $\mathrm{Ng} 2007)$.

\section{Dynamic oscillatory compression}

For each group of 4-5 cells, an AFM probe tip was used to position each individual chondrocyte and its cell-associated matrix into one of the inverted pyramidal wells of a silicon substrate in DMEM (Fig. 1a). We were able to directly observe and choose each single cell on the substrate through the monitor via the optical microscope of AFM, as previously shown in Figure 1(c) of $\mathrm{Ng}$ et al (Ng 2007). A multimode Nanoscope IV AFM with PicoForce piezo (Veeco, Santa Barbara, CA) was then used to perform compression measurements on each cell-matrix composite within its well. Both pyramidal $\left(\mathrm{Si}_{3} \mathrm{~N}_{4}\right.$, cantilever spring constant, $\mathrm{k} \sim 0.06 \mathrm{~N} / \mathrm{m}$, end radius, $\mathrm{R}_{\text {tip }} \sim 50 \mathrm{~nm}, \mathrm{NP}-20$, Veeco) and then spherical colloidal probe tips (Silica beads from Bang Labs, \#SS06N, tipless cantilever from Veeco, NP-020, k 0.06 N/m, $\mathrm{R}_{\text {tip }} \sim 2.5 \mu \mathrm{m}$ ) were used sequentially to probe each cell of the given group of cells on the substrate. For each cell, the probe tip was centered manually (under visual control) over the well where the cellcomposite was placed. Script mode (Nanoscope IV software, V613r1) was programmed to apply a $1 \mu \mathrm{m}$ ramp indentation at a displacement rate of $1 \mu \mathrm{m} / \mathrm{s}$ using both pyramidal and spherical colloidal probe tips ( $\mathrm{Ng}$ 2007). A closed-loop scanner was used to apply the $1 \mu \mathrm{m}$ ramp indentation and subsequently to maintain the indentation depth constant at $1 \mu \mathrm{m}$. Force relaxation at constant displacement was then measured during the subsequent 180 -second interval (Fig. 1b,c). Only z-direction movement at zero x-y offset was allowed during the force mode AFM measurement to avoid crosstalk between AFM x-y and z-direction piezo displacements or $\mathrm{x}-\mathrm{y}$ direction drift. After the force reached quasi-equilibrium within $\sim 100$ seconds, a sinusoidal displacement ( $5 \mathrm{~nm}$ amplitude) was superimposed on the $1 \mu \mathrm{m}$ static offset displacement under closed loop control using an external wave generator (Rockland 5100) connected to the Nanoscope IV controller. The $5 \mathrm{~nm}$ displacement amplitude was determined from the measured z-piezo displacement. The magnitude and phase angle of the resulting force were measured at discrete frequencies of $1,3.16,10,31.6,100$, and $316 \mathrm{~Hz}$ (Fig. 1c). The force magnitude was in the $0.01-0.1 \mathrm{nN}$ range; at lower frequencies $(<1 \mathrm{~Hz})$ was below the AFM detection limit and software limitations prevented testing above $316 \mathrm{~Hz}$. Measurements were repeated 3 times for each of the two probe tip sizes at the same single location of each cell-matrix composite. 4 5 cell-matrix composites from day 7, 14, 21, and 28 
cultures were tested with both probe tips. In addition, 3 day- 0 cells were tested with nanosized probe tips (see Figure S1c).

\section{Data analysis and statistical tests}

Dynamic force and displacement data for both probe tips were analyzed using Fast Fourier Transforms to obtain the magnitude of the complex modulus, $\left|E^{*}(f)\right|$, and phase angle, $\delta(f)$, between measured force and applied displacement. Application of sinusoidal displacements even as low as $5 \mathrm{~nm}$ in amplitude, with either micron-sized or nano-sized probe tips, resulted in measured sinusoidal force waveforms having total harmonic distortion less than 5\% over the entire frequency range of interest. $\delta(f)$ was corrected for the effect of hydrodynamic drag (Alcaraz 2002); the control experiment was performed on the Si substrate covered by culture medium to evaluate the phase angle of the control experiment using both probe tips (See Appendix D). For the micron-sized spherical probe tip, $\left|E^{*}(f)\right|$ was obtained from a Taylor series expansion of the Hertzian contact model (Johnson 1997; Mahaffy 2004):

$$
\left|E_{\text {spherical }}^{*}(f)\right|=\frac{1-v^{2}}{2 \sqrt{R d_{0}}} \frac{F(f)}{d(f)}
$$

where $d_{0}$ is indentation depth at zero frequency, Poisson's ratio, $v$, was initially assumed to be 0.4 (Freeman 1994), $R$ is the effective radius of the probe tip and cell-matrix composite (i.e., $\left.1 / R=\left[1 / R_{\text {spherical tip }}\right]+\left[1 / R_{\text {cell-matrix composite }}\right]\right), F(f)$ is the magnitude of the force at frequency $f$, and $d(f)$ is the magnitude of the deformation at frequency $f$ during dynamic oscillatory compression (Ng 2007) (Fig. 1c). The Hertzian model approximation used in this study is sufficient for assessing relative trends in the temporal evolution of matrix stiffness with culture time, which is the primary focus of this study. The real $\left[E^{\prime}(f)\right]$ and imaginary $\left[E^{\prime \prime}(f)\right]$ parts of the complex modulus (i.e., storage and loss moduli) are also reported, as well as | $\mathrm{E}^{*}$ pyramidal $(f) \mid$ obtained using the pyramidal probe tip (see Appendix A).

To test our working hypothesis that culture duration and GF treatment significantly influence the dynamic properties of cell-matrix composites, each effect (culture duration, GF treatment, frequency and tip geometry) on $\left|\mathrm{E}^{*}(f)\right|$ and $\delta(f)$ was tested using one-way ANOVA followed by Tukey's post hoc test for comparisons. All data are expressed as mean \pm SEM, with $p \leq 0.05$ as statistically significant. Statistical analyses were performed using Systat-12.0 (Richmond CA).

\section{Results \\ Effect of frequency}

$\left|E^{*}\right|$ and $\delta$ increased nonlinearly with applied displacement frequency in both FBS (Fig. 2) and GF (Fig. 3) cultures at each time point. The effect of frequency on $\left|E^{*}\right|$ and $\delta$ was significant for both FBS and GF culture medium with both the spherical micron-sized tip (Figs. 2a,b, 3a,b) and the pyramidal nanosized tip (Figs. 4a,b, 5a,b, 6b) by one-way ANOVA ( $\mathrm{p}<0.05$ ). In FBS, $\left|E^{*}\right|$ and $\delta$ at $316 \mathrm{~Hz}$ were significantly different from that at all lower frequencies during the entire culture period (Fig. 2a,b, p<0.05). Similarly, for the nanosized tip, $\left|E^{*}\right|$ and $\delta$ at $316 \mathrm{~Hz}$ were significantly different from all lower frequencies during the entire culture period for both FBS and GF culture (Fig. 4a,b, 5a,b, p<0.05).

\section{Effect of culture duration}

$\left|E^{*}(f)\right|, E^{\prime}(f), E^{\prime \prime}(f)$ increased and $\delta(f)$ decreased with culture duration. The effect of culture duration on $\left|E^{*}(f)\right|$ and $\delta(f)$ was significant for both FBS and GF medium with the micron-sized (Fig. 2a,b, 3a,b) and nanosized tip (Figs. 4a,b, 5a,b) (one-way ANOVA, p<0.05). For GF 
culture, pair-wise comparisons showed that $\left|E^{*}(f)\right|$ obtained with the micron-size tip on day 14-28 at higher frequencies were significantly higher from that on day $(\mathrm{p}<0.05$ for $316 \mathrm{~Hz}$, p $<0.005$ for $100 \mathrm{~Hz}$ (not shown)). Fig. $6 a$ shows the trend at $316 \mathrm{~Hz}$ between day 7 and day 21 in GF culture with the nanosized tip $(\mathrm{p}<0.05)$.

\section{Effect of GF treatment}

$\left|E^{*}(f)\right|$ and $E^{\prime}(f)$ increased significantly with the addition of GF compared to FBSsupplementation using the micron-sized (Fig. 7a) and nanosized tip (Fig. 6c) (ANOVA, $\mathrm{p}<0.05)$. In GF culture, $\delta(f)$ was significantly lower than that in FBS at both low and high frequencies (1, 100-316 Hz) with the micron-sized (Fig. 7b) and nanosized tip (Fig. 6d) $(\mathrm{p}<0.05)$. Interestingly, the quasi-static force-displacement (indentation) curves of individual chondrocyte-matrix composites (Fig. S1a,b) demonstrated that GF-cultured samples exhibited a much higher indentation stiffness than FBS-cultured samples when utilizing a $1 \mu \mathrm{m}$ indentation displacement. In contrast, while the dynamic stiffness $\left|E^{*}(f)\right|$ measured at $5 \mathrm{~nm}$ displacement amplitude increased significantly with GF-treatment, the increase was modest ( 1.5-fold).

\section{The effect of tip geometry}

$\left|E^{*}(f)\right|$ was not significantly affected by tip geometry in this 28 day culture study. A possible interpretation is that after initial application of the $\sim 1 \mu \mathrm{m}$ deformation, the small amplitude oscillation $(5 \mathrm{~nm})$ involves approximately similar contact areas for both probe tips sizes once embedded within the matrix. In contrast, the matrix stiffness detected using larger $1 \mu \mathrm{m}$ indentation deformation was much larger for the micron-sized colloidal tip (Fig. S1).

\section{Discussion}

An AFM-based single cell mechanics approach revealed that the dynamic mechanical properties of the newly synthesized tissue-engineered matrix-chondrocyte composite are frequency-dependent and change with culture duration and GF treatment. Dynamic oscillatory nanomechanics methods (Mahaffy 2000) were combined with an experimental protocol incorporating an inverted pyramidal Si well (Ng 2007) (Fig. 1a) to hold each cell-matrix composite in place, facilitating a more physiological-like shape. First, the mechanical contributions from the cell and matrix are discussed for the FBS and GF-supplemented systems. Following, the dynamic mechanical data of cells cultured in FBS are discussed, for which the matrix was much softer than that of the cell itself and, hence, the dynamic mechanical properties of the cell-matrix composite are dominated by the properties of the matrix. Scaling approximations are then used to identify the rate-dependent processes and energy dissipation mechanisms that underlie the observed dynamic behavior. Lastly, the effects of culture duration on indentation stiffness versus dynamic stiffness and the effects of GF stimulation are discussed.

\section{Individual contributions from cell and matrix}

Indentation data analyzed from the initial force-displacement (ramp) portion (Fig. 1b) of the experiments (Fig. S1a,c) showed that day 7-28 cell-matrix composites cultured in FBS were much more compliant than day 0 cells with no surrounding matrix, consistent with our previous study (Ng 2007). Finite element analysis of this system by Ng, et al. indicated that with FBS treatment, cell deformation was negligible compared to matrix deformation and, hence, the measured indentation stiffness was dominated by the matrix ( $\mathrm{Ng} 2007)$. Hence, the dynamic mechanical properties reported here for the FBS culture conditions (Fig. 2) can be assumed to be dominated by the properties of the cell-associated matrix. However, for the GF cultures, nanoindentation data (Fig. S1b,d) show that the indentation stiffness of the cell-matrix composite increased substantially over 28 days, eventually approaching the stiffness of the 
day-0 cell with no matrix. Therefore, under dynamic loading conditions, the dynamic mechanical properties of Fig. 3 likely include contributions from both the cell and matrix.

We note that the Poisson's ratio of the cell-matrix composite sensed by the probe tip may vary between day 7 and day 28, and may reflect the properties of both the cell and the cell-associated matrix (Alexopoulos 2005). We used the Poisson's ratio of chondrocytes for our initial calculations $(v=0.4$, (Freeman 1994). For conditions in which the matrix completely dominates the measured $\left|\mathrm{E}^{*}(f)\right|$, a value of $v$ closer to that of the PCM $(v=0.04$, (Alexopoulos 2005) may be more appropriate, which would increase the estimated $\left|\mathrm{E}^{*}(f)\right|$ by $\sim 20 \%$ in magnitude.

\section{Mechanisms underlying dynamic frequency behavior}

In general, the frequency dependence of $\left|E^{*}\right|, E^{\prime}, E^{\prime \prime}$, and $\delta$ may be associated with fluid flowdependent poroelasticity and/or flow-independent viscoelastic processes. To explore these possibilities, we first estimated the characteristic poroelastic relaxation time, $\tau_{\mathrm{p}} \sim\left[\mathrm{L}^{2} /(\mathrm{Hk})\right]$ (also called the 'gel diffusion time') (Mow 1980;Grodzinsky 1981;Lee 1981;Soltz 2000;Morel 2004), where L is the characteristic length scale over which fluid flows, $H$ is the elastic modulus, and $\mathrm{k}$ is the hydraulic permeability of the cell-associated matrix. $\mathrm{L}$ can be approximated as the radius of the probe tip, $2.5 \mu \mathrm{m}$ (see Supplementary Appendix D for detailed discussion); H is approximated by quasi-static indentation modulus, $~ 0.12 \mathrm{kPa}$ for day 14 and $0.17 \mathrm{kPa}$ for day 28 (Ng 2007); and $\mathrm{k}$ can be estimated from the measured GAG content ( $\mathrm{Ng} 2007)$ to be $\sim 6.6 \times 10^{-12} \mathrm{~m}^{4} / \mathrm{N} \cdot \mathrm{s}$ for day 14 and $1.7 \times 10^{-12} \mathrm{~m}^{4} / \mathrm{N} \cdot \mathrm{s}$ for day 28 in FBS culture by using the unit cell model (Happel 1959;Eisenberg 1988) assuming that GAGs are the primary determinant of the permeability (see Appendix C). $\tau_{\mathrm{p}}$ of the newly developing matrix was thereby estimated to be $\sim 0.01-0.02 \mathrm{~s}$ from days $14-28$, corresponding to characteristic frequencies $f_{p} \sim\left[1 / \tau_{\mathrm{p}}\right]$ of $50-90 \mathrm{~Hz}$, which is within the $1-316 \mathrm{~Hz}$ range of the testing frequencies of the present experiments and, in part, motivated the range of testing frequencies used.

Previous measurements and poroelastic models of the dynamic stiffness of native cartilage (Frank 1987; Kim 1995; Soltz 2000) have shown that $\left|E^{*}\right|$ increases with $f^{1 / 2}$ in the neighborhood of $f_{p} \cdot\left|E^{*}\right|$ in the entire $1-316 \mathrm{~Hz}$ range of Figs. 2a,3a does, indeed, show an $f^{1 / 2}$ dependence $\left(\mathrm{R}^{2}>0.94, \mathrm{p}<0.001\right)$. This result, coupled with the value of $f_{p}$ estimated above, suggests the importance of poroelastic behavior in the experimentally tested frequency range. Interestingly, for native cartilage explants, $\mathrm{H}$ is much larger and $\mathrm{k}$ much smaller than the cell-associated matrix, but the $[\mathrm{Hk}]$ product is on the same order $\left(10^{-9} \mathrm{~m}^{2} / \mathrm{s}\right)$. However, the much larger $\mathrm{L} \sim 1$ $\mathrm{mm}$ for cartilage explants tested in confined or unconfined compression results in frequencies $f_{p}$ that are several orders of magnitude lower for the dynamic behavior of cartilage (0.001-0.01Hz) in confined or unconfined compression (Kim 1995; Buschmann 1999; Huang 2003). In contrast to this mm-length-scale testing, application of dynamic oscillatory compression to bovine cartilage explants using the micron-sized AFM probe tips again resulted in higher characteristic frequencies $\left(f_{\mathrm{p}} \sim 100 \mathrm{~Hz}\right)$ (Han 2008), on the same order as that observed in the present study. For cartilage explants tested at the macroscale (Kim 1995), it was possible to perform experiments at frequencies $\mathrm{f} \gg f_{\mathrm{p}}$ where it was observed that $\delta(f)$ would begin to decrease with increasing frequency. It would therefore be very useful to obtain dynamic stiffness data for the cell-associated matrix at higher frequencies up to the $10 \mathrm{kHz}$ range to more fully compare with theoretical predictions (Kim 1995). At present, however, AFM instrumentation limits data acquisition beyond a maximum frequency of $\sim 350 \mathrm{~Hz}$. The values of $\mathrm{H}$ and $\mathrm{k}$ estimated for our matrix may, indeed, reflect the structure and organization observed in previous studies (Lee 1998; DiMicco 2007) in which newly developing matrix revealed more diffusive and porous morphologies than that of freshly isolated, mature chondrons (Lee 1998). At the same time, intrinsic viscoelastic behavior associated with macromolecular constituents (Flory 1953) may also contribute to the frequency-dependent behavior of the newly developing matrix. 


\section{Effect of culture duration}

The increase in $\left|E^{*}(f)\right|$ with time in culture is consistent with our previously measured increase in biosynthesis and deposition of GAG and collagen within the cell-associated matrix ( $\mathrm{Ng}$ 2007). The decrease in $\delta(f)$ with culture duration corresponds to a decrease in energy dissipation during dynamic compression (i.e., a more elastic-like response), consistent with increased biomacromolecular deposition and altered matrix structure/organization (e.g., physical crosslinking, macromolecular entanglements). $\mathrm{k}$ is also predicted to decrease with culture time (Appendix C), indicative of a denser matrix structure. It is hypothesized that the modest increase in $\left|\mathrm{E}^{*}(f)\right|$ and the decrease in $d(f)$ with culture time compared to the quasi-static indentation stiffness may be due to the fact that the newly developing matrix is more sensitive to the higher compaction associated with the $1 \mu \mathrm{m}$ indentation displacement compared to the much smaller $\sim 5 \mathrm{~nm}$ dynamic displacement amplitude.

\section{Effect of GF treatment}

The increase in $\left|\mathrm{E}^{*}(f)\right|$ and decrease in $\mathrm{d}(f)$ with GF treatment compared to FBS at the applied frequency range again suggests a more elastic-like response likely due to compositional and structural changes, including proteoglycan accumulation (Buschmann 1992; Mauck 2000; DiMicco 2007). The effect of GF treatment on $\left|E^{*}(f)\right|$ (Fig. 2a,3a) was modest compared to the more dramatic increase in the indentation stiffness (Fig. S1), suggesting that the effect of GF on functional mechanical properties is sensitive to the magnitude of the applied displacement.

In summary, our AFM-based approach has enabled the measurement of the poroelastic dynamic mechanical behavior of the newly developing matrix associated with individual chondrocytes, and can be applied generally to study the dynamic behavior of extremely compliant ( $\sim \mathrm{kPa})$ biological, porous, and hydrated systems at nm-length scales over a broad range of frequencies. The high resolution dynamic mechanical approach described here is able to discern fine differences in the development and maturation of the cell-associated matrix temporally and with the addition of growth factors. The methodologies reported here can thus be employed to assess maturation of matrix synthesized by primary chondrocytes and, additionally, by other cells such as stem cells undergoing chondrogenesis in applications for cartilage tissue engineering. It may also be possible to use this methodology to study the mechanobiological response of single chondrocytes (Shieh 2006) and stem cells to applied dynamic loads over a wide frequency range

\section{Supplementary Material}

Refer to Web version on PubMed Central for supplementary material.

\section{Acknowledgments}

Supported by NSF-NIRT 0403903, NSF-CMMI 0758651, NIH Grant AR33236, and US Army through the MIT Institute for Soldier Nanotechnologies (contract number DAAD-19-02-D0002). The content does not necessarily reflect the position of the government and no official endorsement should be inferred.

\section{Abbreviations}

$\begin{array}{ll}\text { AFM } & \text { atomic force microscopy } \\ \text { PCM } & \text { pericellular matrix } \\ \text { ECM } & \text { extracellular matrix } \\ \text { FBS } & \text { fetal bovine serum } \\ \text { IGF-1 } & \text { insulin-like growth factor }\end{array}$




$\begin{array}{ll}\text { OP-1 } & \text { osteogenic protein-1 } \\ \text { GF } & \text { growth factor } \\ \text { IGF } & \\ \text { SEM } & \text { standard error of mean }\end{array}$

\section{References}

Alcaraz J, Busceme L, Puig-de-Morales M, Colchero J, Baró A, Navajas D. Correction of microrheological measurements of soft samples with atomic force microscopy for the hydrodynamic drag on the cantilever. Langmuir 2002;18:716-721.

Alcaraz J, Buscemi L, Grabulosa M, Trepat X, Fabry B, Farre R, Navajas D. Microrheology of human lung epithelial cells measured by atomic force microscopy. Biophys J 2003;84:2071-2079. [PubMed: 12609908]

Alexopoulos LG, Haider MA, Vail TP, Guilak F. Alterations in the mechanical properties of the human chondrocyte pericellular matrix with osteoarthritis. J Biomech Eng 2003;125:323-333. [PubMed: 12929236]

Alexopoulos LG, Williams GM, Upton ML, Setton LA, Guilak F. Osteoarthritic changes in the biphasic mechanical properties of the chondrocyte pericellular matrix in articular cartilage. J Biomech 2005;38:509-517. [PubMed: 15652549]

Buschmann MD, Gluzband YA, Grodzinsky AJ, Hunziker EB. Mechanical compression modulates matrix biosynthesis in chondrocyte/agarose culture. J Cell Sci 1995;108:1497-1508. [PubMed: 7615670]

Buschmann MD, Gluzband YA, Grodzinsky AJ, Kimura JH, Hunziker EB. Chondrocytes in agarose culture synthesize a mechanically functional extracellular matrix. J Orthopaedic Res 1992;10:745758.

Buschmann MD, Grodzinsky AJ. A molecular model of proteoglycan-associated electrostatic forces in cartilage mechanics. J Biomech Eng 1995;117:179-192. [PubMed: 7666655]

Buschmann MD, Kim Y-J, Wong M, Frank E, Hunziker EB, Grodzinsky AJ. Stimulation of aggrecan synthesis in cartilage explants by cyclic loading is localized to regions of high interstitial fluid flow. Arch Biochem Biophys 1999;366(1):1-7. [PubMed: 10334856]

Chao PG, Tang Z, Angelini E, West AC, Costa KD, Hung CT. Dynamic osmotic loading of chondrocytes using a novel microfluidic device. J Biomech 2005;38:1273-1281. [PubMed: 15863112]

Darling EM, Zauscher S, Guilak F. A thin-layer model for viscoelastic, stress-relaxation testing of cells using atomic force microscopy: do cell properties reflect metastatic potential? Biophys J 2007;92:1784-1791. [PubMed: 17158567]

DiMicco MA, Kisiday JD, Gong H, Grodzinsky AJ. Structure of pericellular matrix around agaroseembedded chondrocytes. Osteoarthr Cartilage 2007;15(10):1207-1216.

Dudhia J. Aggrecan, aging and assembly in articular cartilage. Cell Mol Life Sci 2005;62:2241-2256. [PubMed: 16143826]

Eisenberg SR, Grodzinsky AJ. Electrokinetic micromodel of extracellular matrix and other polyelectrolyte networks. Physicochem Hydrodyn 1988;10(4):517-539.

Flory, PJ. Principles of Polymer Chemistry. Cornell Univ. Press; Ithaca: 1953. Configurational and frictional properties of the polymer molecule in dilute solution; p. 595-639.

Frank EH, Grodzinsky AJ. Cartilage Electromechanics - II. Continuum model of cartilage electrokinetics and correlation with experiments. J Biomech 1987;20:629-639. [PubMed: 3611138]

Freeman PM, Natarajan RN, Kimura JH, Andriacchi TP. Chondrocyte cells respond mechanically to compressive loads. J Orthopaedic Res 1994;12:311-320.

Grodzinsky AJ, Roth V, Myers E, Grossman WD, Mow VC. The significance of electromechanical and osmotic forces in the nonequilibrium swelling behavior of articular cartilage in tension. J Biomech Eng 1981;103:221-231. [PubMed: 7311487] 
Han, L.; Greene, JJ.; Frank, EH.; Hung, H-HK.; Grodzinsky, AJ.; Ortiz, C. Effect of length scale on frequency-dependent cartilage oscillatory nanomechanics; 54th Annual Meeting of the Orthopaedic Research Society; San Francisco, CA. 2008.

Happel J. Viscous flow relative to arrays of cylinders. AIChE J 1959;5(2):174-177.

Huang C-Y, Soltz MA, Kopacz M, Ateshian GA. Experimental verification of the roles of intrinsic matrix compression nonlinearity in the biphasic response of cartilage. J Biomech Eng 2003;125:84-93. [PubMed: 12661200]

Huang W, Anvari B, Torres JH, LeBaron RG, Athanasiou KA. Temporal effects of cell adhesion on mechanical characteristics of the single chondrocyte. J Orthop Res 2003;21:88-95. [PubMed: 12507584]

Johnson KL, Greenwood JA. An adhesion map for the contact of elastic spheres. J Colloid Interface Sci 1997;192:326-333. [PubMed: 9367554]

Kim E, Guilak F, Haider MA. The dynamic mechanical environment of the chondrocyte: a biphasic finite element model of cell-matrix interactions under cyclic compressive loading. J Biomech Eng 2008;130:1-10. 061009.

Kim Y-J, Bobassar LJ, Grodzinsky AJ. The role of cartilage streaming potential, fluid flow and pressure in the stimulation of chondrocyte biosynthesis during dynamic compression. J Biomech 1995;28(9): 1055-1066. [PubMed: 7559675]

Lee GM, Johnstone B, Jacobson K, Caterson B. The dynamic structure of the pericellular matrix on living cells. J Cell Biol 1993;123(6):1899-1907. [PubMed: 8276905]

Lee GM, Loeser RF. Interactions of the chondrocyte with its pericellular matrix. Cell Mater 1998;8:135149.

Lee RC, Frank EH, Grodzinsky AJ, Roylance DK. Oscillatory compressional behavior of articular cartilage and its associated electromechanical properties. J Biomech Eng 1981;103:280-292. [PubMed: 7311495]

Loeser RF, Pacione CA, Chubinskaya S. The combination of insulin-like growth factor 1 and osteogenic protein 1 promotes increased survival of and matrix synthesis by normal and osteoarthritic human articular chondrocytes. Arthritis Rheum 2003;48:2188-2196. [PubMed: 12905472]

Mahaffy RE, Park S, Gerde E, Käs J, Shih CK. Quantitative analysis of the viscoelastic properties of thin regions of fibroblasts using atomic force microscopy. Biophys J 2004;86:1777-1793. [PubMed: 14990504]

Mahaffy RE, Shih CK, MacKintosh FC, Käs J. Scanning probe-based frequency-dependent microrheology of polymer gels and biological cells. Phys Rev Lett 2000;85(4):880-883. [PubMed: 10991422]

Maroudas A, Mizrahi J, Ben Haim E, Ziv I. Swelling pressure in cartilage. Adv Microcirc 1987;13:203212.

Mauck RL, Soltz MA, Wang CCB, Wong DD, Chao P-HG, Valhmu WB, Hung CT, Ateshian GA. Functional tissue engineering of articular cartilage through dynamic loading of chondrocyte-seeded agarose gels. J Biomech Eng 2000;122:252-260. [PubMed: 10923293]

Millward-Sadler SJ, Salter DM. Integrin-dependent signal cascades in chondrocyte mechanotransduction. Ann Biomed Eng 2004;32(3):435-446. [PubMed: 15095818]

Millward-Sadler SJ, Wright MO, Davies LW, Nuki G, Salter DM. Mechanotransduction via integrins and interleukin-4 results in altered aggrecan and matrix metalloproteinase 3 gene expression in normal, but not osteoarthritic, human articular chondrocytes. Arthritis Rheum 2000;43(9):20912099. [PubMed: 11014361]

Morel V, Quinn TM. Cartilage injury by ramp compression near the gel diffusion rate. J Orthopaedic Res 2004;22:145-151.

Mow VC, Kuei SC, Lai WM, Armstrong CG. Biphasic creep and stress relaxation of articular cartilage in compression: theory and experiments. J Biomech Eng 1980;102(73):73-84. [PubMed: 7382457]

Ng L, Hung H-H, Sprunt A, Chubinskaya S, Ortiz C, Grodzinsky AJ. Nanomechanical properties of individual chondrocytes and their developing growth factor-stimulated pericellular matrix. J Biomech 2007;40(5):1011-1023. [PubMed: 16793050]

Park S, Koch D, Cardenas R, Käs J, Shih CK. Cell motility and local viscoelasticity of fibroblasts. Biophys J 2005;89:4330-4342. [PubMed: 16199496] 
Radmacher M. Measuring the elastic properties of biological samples with the AFM. IEEE Eng Med Biol 1997;16(2):47-57.

Shepherd DET, Seedhom BB. A technique for measuring the compressive modulus of articular cartilage under physiological loading rates with preliminary results. Pro Instn Mech Engrs Part H 1997;211:155-165.

Shieh AC, Athanasiou KA. Biomechanics of single zonal chondrocytes. J Biomech 2006;39:1595-1602. [PubMed: 15992803]

Shieh AC, Athanasiou KA. Dynamic compression of single cells. Osteoarthr Cartilage 2006;15(3):328324.

Smith B, Tolloczko B, Martin J, Grutter P. Probing the viscoelastic behavior of cultured airway smooth muscle cells with atomic force microscopy: stiffening induced by contractile agonist. Biophys J 2005;88:2994-3007. [PubMed: 15665124]

Soltz MA, Ateshian GA. Interstitial fluid pressurization during confined compression cyclical loading of articular cartilage. Ann Biomed Eng 2000;28:150-159. [PubMed: 10710186]

Trickey WR, Vail TP, Guilak F. The role of the cytoskeleton in the viscoelastic properties of human articular chondrocytes. J Orthop Res 2004;22:131-139. [PubMed: 14656671] 
(a)
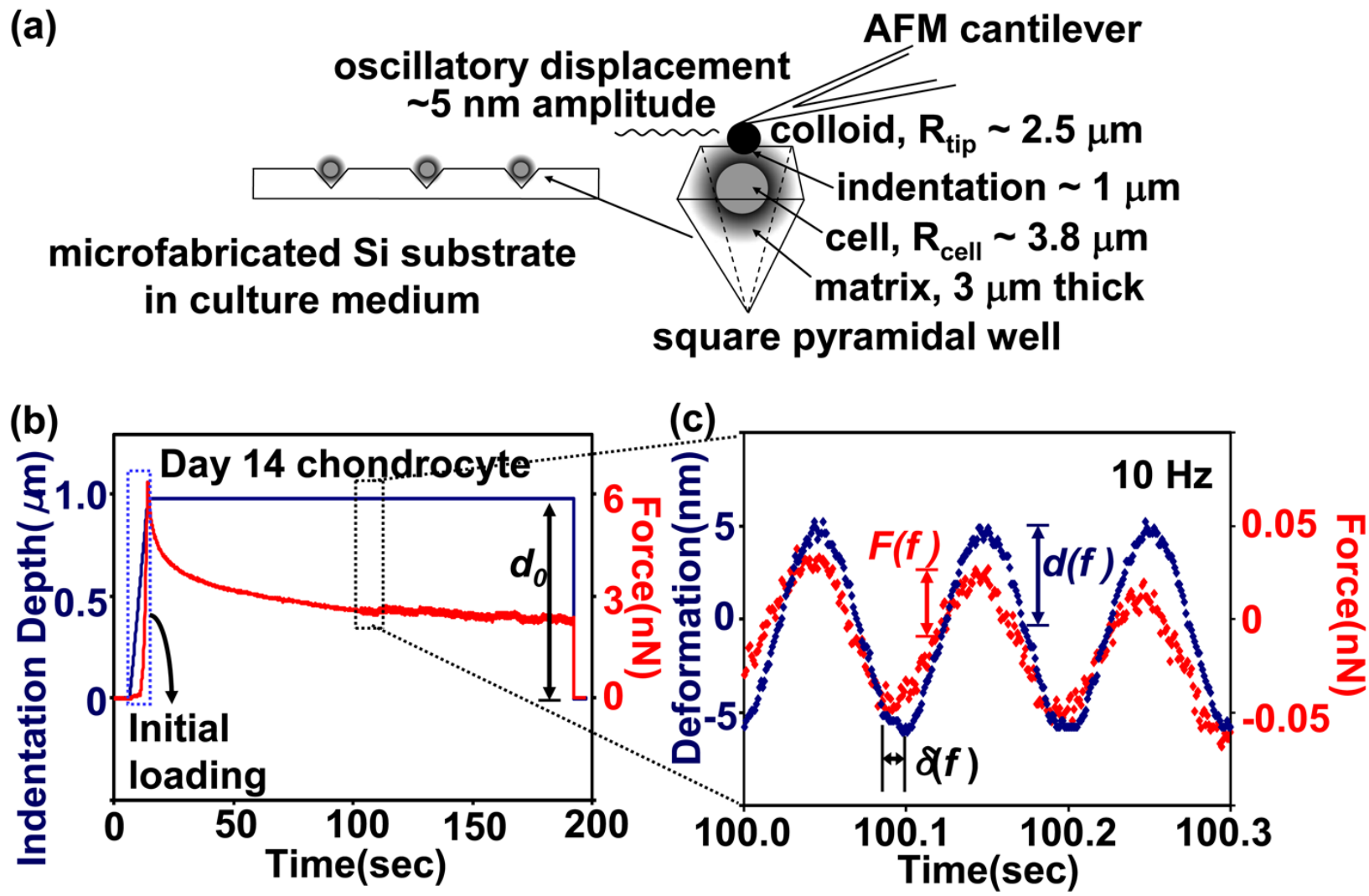

Figure 1.

Dynamic oscillatory compression of individual chondrocytes and their associated matrix in FBS culture using a spherical tip: (a) Experimental setup: Chondrocyte-matrix composites in microfabricated silicon wells (radius of cell $=R_{\text {cell }}$, radius of probe tip $=R_{\text {tip }}$, matrix thickness $=3 \mu \mathrm{m}$, indentation depth $=1 \mu \mathrm{m}$, and small sinusoidal oscillation $=5 \mathrm{~nm}$; the detailed structure of the matrix has been described previously (Lee 1993;Dudhia 2005)), (b) Force (red) and indentation depth (blue) curve showing the initial indentation (depth, $\mathrm{d}_{0}=1 \mu \mathrm{m}$ ) and subsequent force relaxation exemplified by a day 14 chondrocyte, and (c) inset showing the applied dynamic sinusoidal deformation $(\mathrm{d}(f))$ and resulting dynamic force $(\mathrm{F}(f))$ shifted from the displacement by the phase angle $\delta(f)$. 

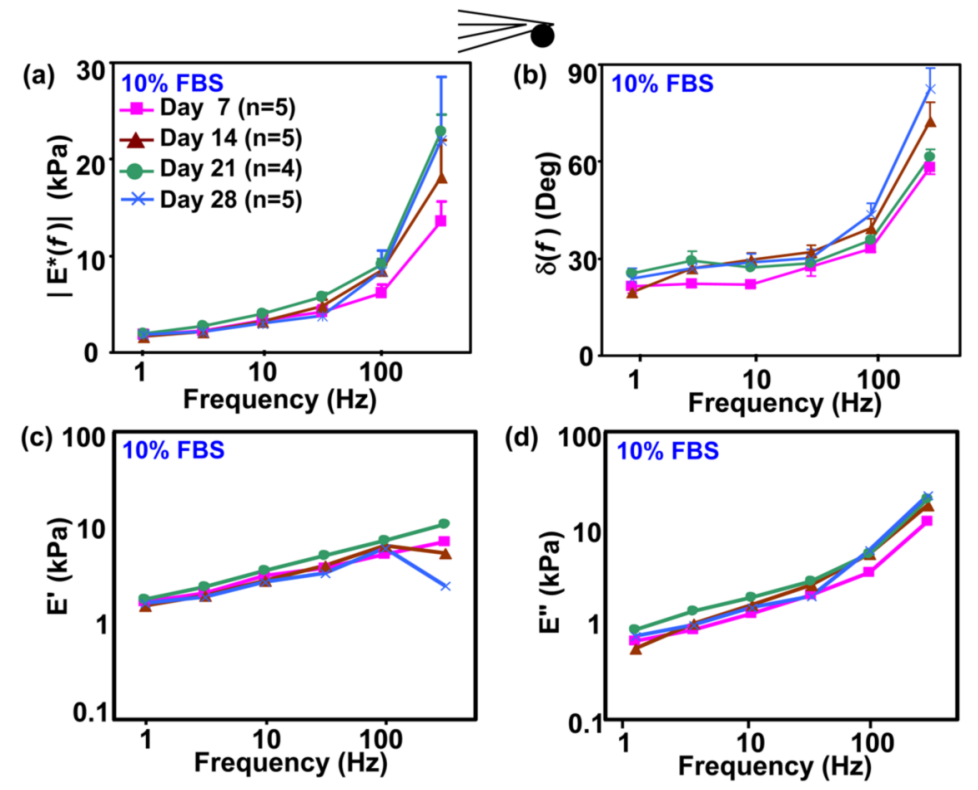

Figure 2.

Dynamic mechanical properties of chondrocytes and their newly developing cell-associated matrix up to 28 days in FBS culture $\left(10 \%\right.$ FBS) using the spherical probe tip: (a) $\left|E^{*}(f)\right|$, (b) $\delta$ $(f)$, (c) $E^{\prime}(f)$ and (d) $E^{\prime \prime}(f)$. n=number of cells, mean \pm SEM; maximum SEM is $\sim 4 \mathrm{kPa}$ for $E^{\prime}$ $(f)$ and $\sim 6 \mathrm{kPa}$ for $E^{\prime \prime}(f)$, respectively. 

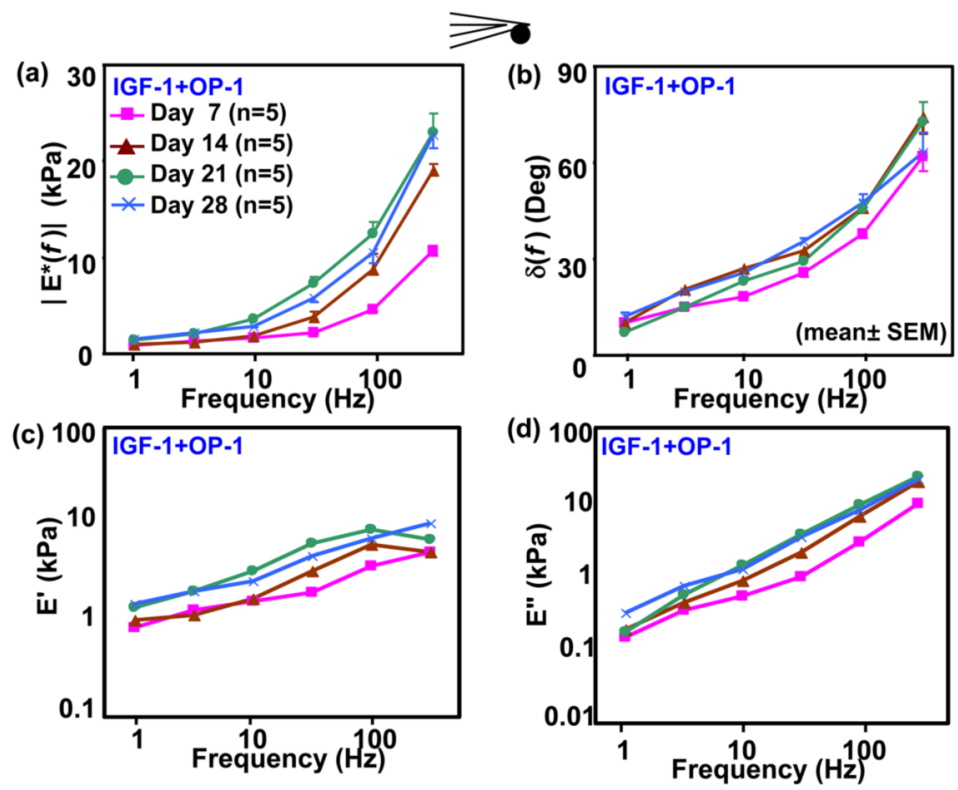

Figure 3.

Dynamic mechanical properties of chondrocytes and their cell-associated matrix up to 28 days in GF culture (IGF-1+OP-1) using the spherical probe tip: (a) $\left|E^{*}(f)\right|$, (b) $\delta(f)$, (c) $E^{\prime}(f)$ and (d) $E^{\prime \prime}(f)$. n=number of cells, mean $\pm \mathrm{SEM}$; maximum SEM is $\sim 2 \mathrm{kPa}$ for $E^{\prime}(f)$ and $\sim 1 \mathrm{kPa}$ for $E^{\prime \prime}$ $(f)$, respectively. 

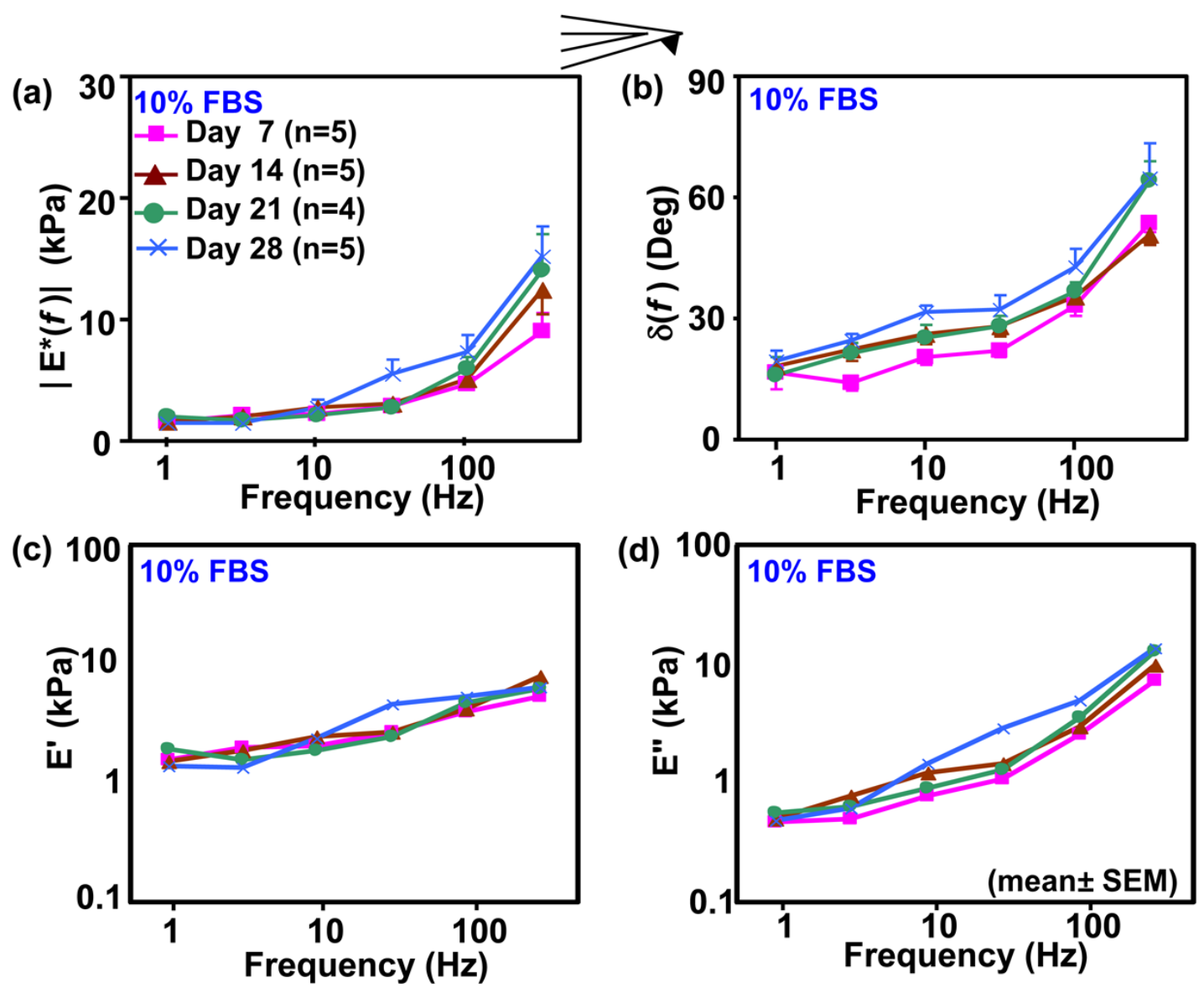

Figure 4.

Dynamic mechanical properties of chondrocytes and their newly developed matrix up to 28 days in FBS culture using the pyramidal probe tip: (a) $\left|E^{*}(f)\right|$, (b) $\delta(f)$, (c) $E^{\prime}(f)$ and (d) $E^{\prime \prime}(f)$. $\mathrm{n}=$ number of cells, mean $\pm \mathrm{SEM}$; maximum SEM is $\sim 2 \mathrm{kPa}$ for $E^{\prime}(f)$ and $\sim 3 \mathrm{kPa}$ for $E^{\prime \prime}(f)$, respectively. 
(a) 30 IGF-1+OP-1
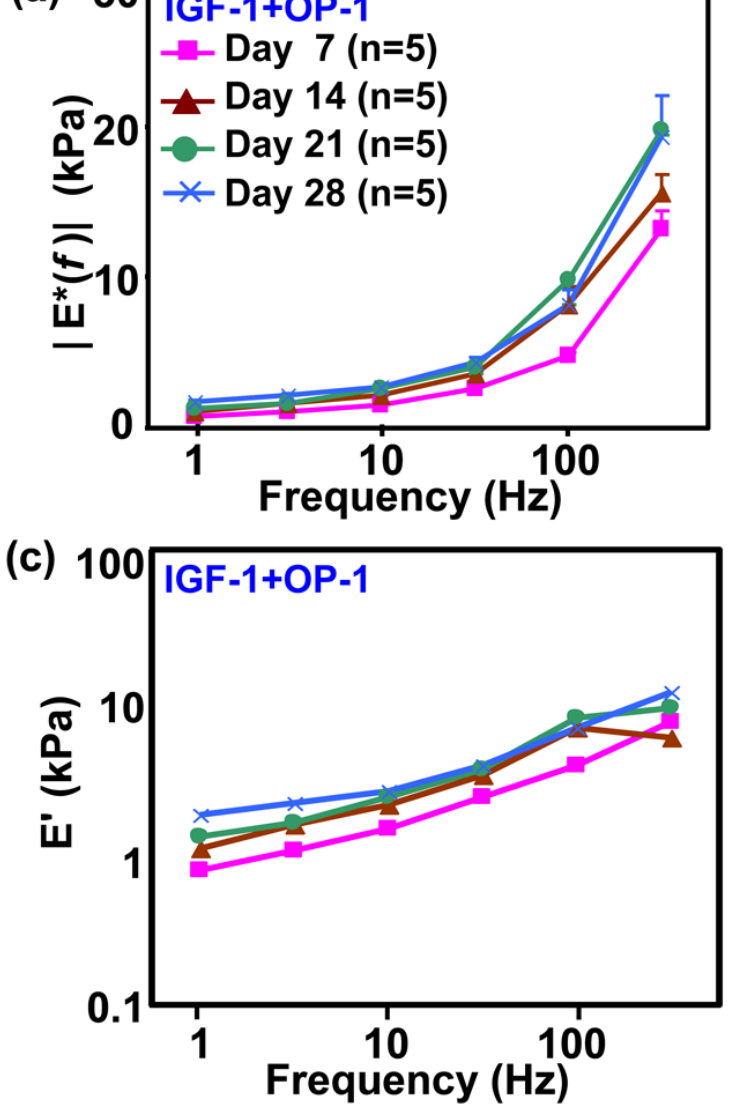

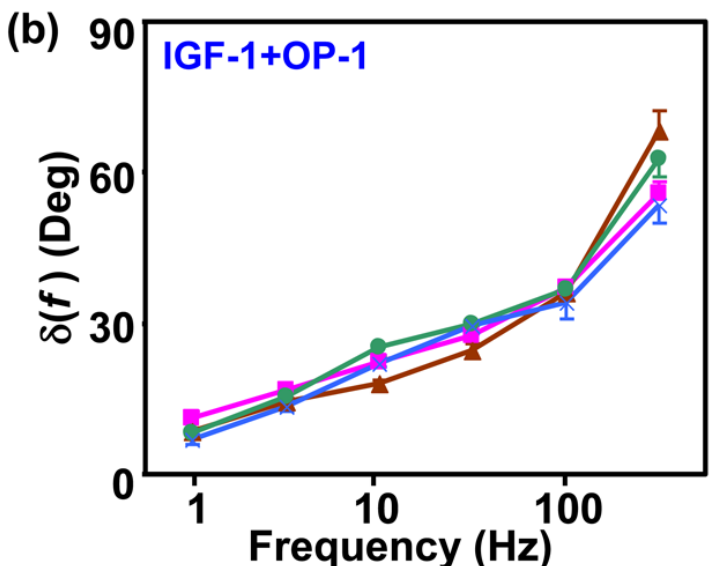

(d)

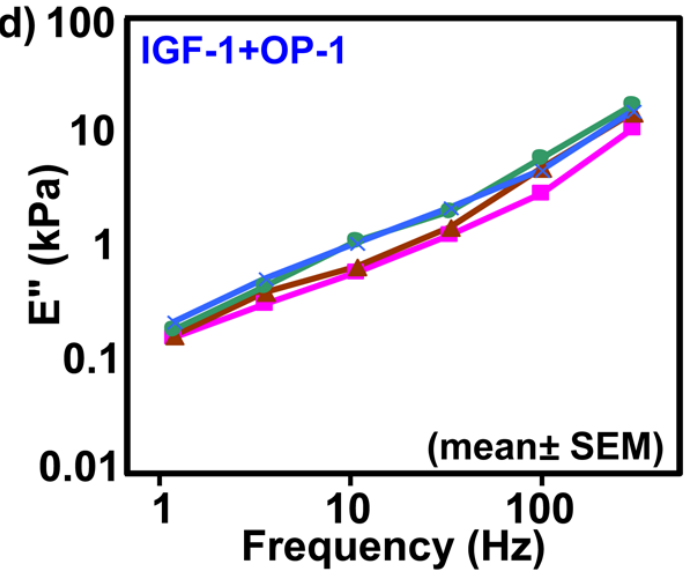

Figure 5.

Dynamic mechanical properties of chondrocytes and their cell-associated matrix up to 28 days in GF culture (IGF-1+OP-1) using the pyramidal probe tip: (a) $\left|E^{*}(f)\right|$, (b) $\beta(f)$, (c) $E^{\prime}(f)$ and (d) $E^{\prime \prime}(f)$. n=number of cells, mean $\pm \mathrm{SEM}$; maximum SEM is $\sim 2 \mathrm{kPa}$ for both $E^{\prime}(f)$ and $E^{\prime \prime}(f)$. 

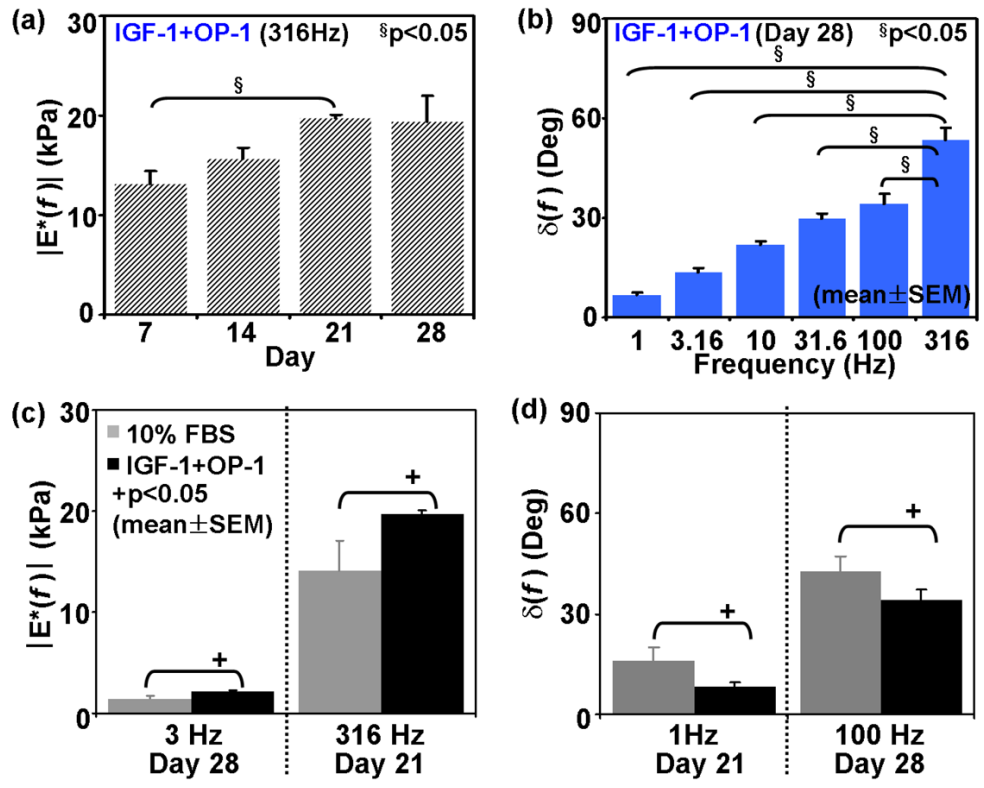

Figure 6.

Effect of culture duration and growth factor treatment on dynamic oscillatory properties using the pyramidal probe tip: (a) the effect of culture duration on $\left|E^{*}(f)\right|$ for GF culture chondrocytes (one-way ANOVA: culture duration), (b) the effect of frequency on $\delta(f)$ for GF culture chondrocytes (one-way ANOVA: frequency), (c) the effect of growth factor treatment on $\mid E^{*}$ $(f)$, and (d) the effect of growth factor treatment on $\delta(f)$ (one-way ANOVA: GF treatment). 


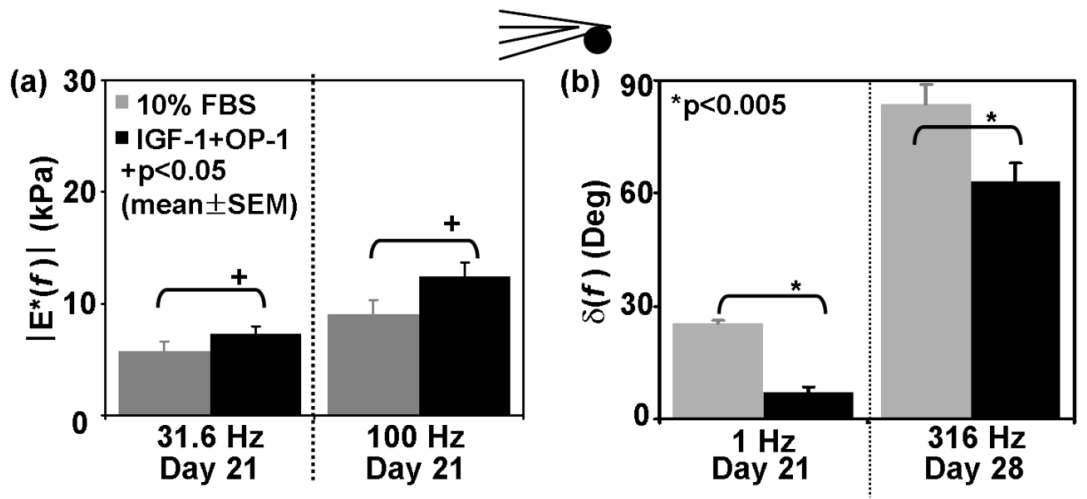

Figure 7.

Effect of culture duration and growth factor treatment on dynamic oscillatory properties of chondrocytes and their newly developing matrix using the spherical probe tip: (a) the effect of growth factor treatment on $\left|E^{*}(f)\right|$ and (b) the effect of growth factor treatment on $\delta(f)$ (oneway ANOVA: GF treatment). 